\title{
CONSTRUINDO APLICATIVOS PARA O ENSINO DE MATEMÁTICA UTILIZANDO O SOFTWARE DE PROGRAMAÇÃO APP INVENTOR
}

ANA PAULA DE ANDRADE JANZ ELIAS

Universidade Tecnológica Federal do Paraná

E-mail: anapjanz777@gmail.com

FLAVIA SUCHECK MATEUS DA ROCHA

Universidade Federal do Paraná

E-mail: fsucheck@yahoo.com.br

MARCELO SOUZA MOTTA

Universidade Tecnológica Federal do Paraná

E-mail: marcelomotta@utfpr.edu.br

\section{MARCO AURÉLIO KALINKE}

Universidade Federal do Paraná

E-mail: kalinke@utfpr.edu.br

RESUMO:

As tecnologias móveis podem ser exploradas em sala de aula através de diferentes abordagens. A utilização de aplicativos para celulares pode ser uma estratégia para utilização dessas tecnologias. 0 software App Inventor permite a criação de aplicativos personalizados, possibilitando que diferentes usuários programem sem a necessidade de formação em programação. Apresentar algumas possibilidades de utilização do mesmo nas aulas de matemática é o intuito deste trabalho, que traz duas experiências desenvolvidas em um colégio da rede privada de ensino de Curitiba: programação e utilização de aplicativos voltados aos conteúdos de Sequências Numéricas e Progressão Aritmética. Utilizamos uma metodologia qualitativa e, apresentamos como ocorreu a programação dos aplicativos, a utilização dos mesmos em sala de aula, suas contribuições e o feedback apresentado pelos alunos. Percebemos a facilidade que os professores tiveram ao programar a partir do software App Inventor com o intuito de trabalhar conteúdos matemáticos de forma mais atrativa para alunos, que demonstraram bastante interesse em trabalhar com a proposta apresentada.

PALAVRAS-CHAVE:

App Inventor; Aplicativos para Celular; Ensino de Matemática; Tecnologias Educacionais.

\section{APP INVENTOR: BUILDING APPLICATIONS FOR MATHEMATICS TEACHING}

\section{ABSTRACT:}

Mobile technologies can be explored in the classroom through different approaches. Using mobile apps can be a strategy for using these technologies. App Inventor software allows the creation of 
custom applications, permitting different users to program without programming training. The purpose of this article is to present some possibilities of using it in mathematics classes, which brings two experiences developed in a private college in Curitiba: programming and use of applications focused on the contents of Numerical Sequences and Arithmetic Progression. We use a qualitative and present how the programming of the applications occurred, their use in the classroom, their contributions, and the students' feedback. We realized the ease that the teachers had when programming from the App Inventor software to work mathematical content more attractively for students interested in working with the presented proposal.

\section{KEYWORDS:}

App Inventor; Mobile Applications; Mathematics Education; Educational Technologies.

\section{INTRODUÇÃO}

É possível perceber que as tecnologias compõem o cotidiano de nossa sociedade em diferentes espaços. Dentro das casas, nas ruas dos bairros, no centro das cidades, nos ambientes escolares, nos ambientes profissionais, é viável utilizar diferentes tecnologias, como cita Cox (2003, p. 12):

A presença da informática no cotidiano atual desafia o homem a voltar-se à exploração dos instrumentos computacionais, assim como, outrora, os elementos naturais que compunham nosso entorno despertavam o interesse do "homem das cavernas".

A autora pontua os desafios trazidos pela informática para o homem e, essa informática, tratada aqui como tecnologia, vem se desenvolvendo a cada novo dia, trazendo consigo diferentes desafios. Alguns dos quais surgem quando as tecnologias são incorporadas ao contexto escolar, pois somente inseri-las dentro deste espaço nem sempre oportuniza a aprendizagem. Cappelin et al (2015, p. 55) aponta:

[...] não basta inserir uma nova tecnologia no ambiente escolar. Para, além disso, é necessário o seu uso de forma consciente, objetivando que ela seja um diferencial e não mais uma novidade passageira que traga mais dificuldades à já complexa rotina do professor. As TD devem servir para possibilitar ações novas, tanto cognitivas quanto motoras, que não eram possíveis ou viáveis, de serem realizadas sem elas.

Nesse contexto, percebemos que as Tecnologias Móveis, tais como smartphones, tablets e notebooks que, segundo Gadanidis, Borba e Scucuglia (2015), tiveram seu uso popularizado efetivamente nos últimos anos em nossa sociedade, e 
isto pode favorecer "novas ações" dentro da sala de aula, uma vez que a mobilidade das mesmas já traz, junto a sua utilização, diferenciais para a rotina de pedagógica.

Diante disso, e do fato de que os estudantes estão frequentemente conectados, percebemos a importância da inserção pedagógica dessas tecnologias como os celulares. A escola precisa caminhar juntamente com as inovações da sociedade, "a presença da Ciência e da tecnologia no mundo contemporâneo parece, por si só, justificar a necessidade de seu ensino [...]" (ANGOTTI, 2015, p.7).

Oliveira (2016) pontua que a utilização das Tecnologias Móveis como celulares e tablets dentro das escolas pode acontecer de forma motivadora e facilitadora, e cita ainda que existe um grande potencial na utilização desses equipamentos. Isso é algo que muitos professores de matemática buscam para suas aulas.

Aproximar o cotidiano do aluno, com a realidade escolar, faz-se então necessário, já que "de um lado, a escola se torna cada vez mais enfadonha para seus alunos e um espaço de trabalho sem sentido para os docentes. Por outro, a tecnologia está se tornando sedutora, onipresente e acessível fora das paredes da escola" (BRANDÃO; VARGAS, 2016, p. 41).

Para Valente (1999) a informática na educação deve acontecer de tal forma que o professor tenha conhecimento sobre as potencialidades da mesma dentro do espaço escolar, sendo capaz de alternar coerentemente diferentes atividades. Cabe ao professor identificar o potencial de utilização dessas ferramentas ao trabalhar diferentes conteúdos matemáticos. Para que esse profissional realize alternâncias de atividades, ele pode fazer uso das Tecnologias Móveis, que possibilitam uma maior mobilidade, que como destacam Ferreira e Mattos (2015),

Trata-se da necessidade de estar sempre em movimento, adaptado para uma constante mudança, como nômades, mas permanecendo constantemente conectados. Nesse sentido, jovens do mundo todo têm encontrado na comunicação móvel um meio privilegiado para se 
expressarem, em consonância com seus modos de ser. (FERREIRA; MATTOS, 2015, p. 277).

Para os autores, os jovens percebem que a comunicação móvel está em harmonia com seu modo de ser, caminha junto com seu desenvolvimento. Essas tecnologias deixaram de ser apenas um meio de comunicação. Existe uma nova cultura na sociedade que está inserida nesse ambiente de Tecnologias Móveis.

Utilizar recursos de Tecnologia Móvel ao longo das aulas de matemática pode propiciar aos alunos um envolvimento mais pessoal com a disciplina. Cabe ao professor perceber que essa tecnologia, assim como a informática, citada por Motta e Silveira (2010), está a serviço do ensino da matemática, trazendo aos alunos uma visão diferente da disciplina. Esses recursos podem ainda enriquecer as práticas pedagógicas através da exploração, criatividade, ludicidade, raciocínio lógico, interatividade, socialização, afetividade e reflexão.

Para Lévy (1993), as inovações que a informática trazia no passado já abriam possibilidades de relações novas entre os homens e os computadores. E, ainda hoje, os computadores têm códigos de programação que se apresentam mais intuitivos, realizam comunicação em tempo real, têm novos princípios de interfaces e dizem respeito aos seres humanos. Nesse sentido, o software App Inventor possibilita a programação de aplicativos para Tecnologias Móveis de forma bastante intuitiva, permitindo novas relações entre a tecnologia e o homem, conforme destacado por Lévy.

O App Inventor é um recurso gratuito para criação de aplicativos para celulares e tablets que possuam o sistema operacional Android. É possível acessar esse software a partir de qualquer navegador (como Internet Explorer, Google Chrome, Mozilla Firefox, entre outros). Barbosa (2016, p.28) comenta:

O App Inventor [...] é uma plataforma de desenvolvimento que permite pessoas com qualquer nível de experiência em programação criarem 
programas (aplicações) para o sistema operacional Android. Ele usa uma interface gráfica onde a funcionalidade dos componentes é exposta aos desenvolvedores via blocos de código permitindo construir o aplicativo sem ter que escrever código tradicional, tal como montar um quebra-cabeça.

Sua programação é simples, e ocorre por meio de blocos (como peças de quebra-cabeça), tornando-se acessível a diferentes tipos de públicos. Para os usuários que pretendem programar a partir desse software é necessário fazer um cadastro rápido na plataforma, ter um e-mail e conexão com a internet. Porém, é possível utilizar os aplicativos desenvolvidos, após serem instalados no Android, de forma offline, maximizando o seu potencial. Usuários que já possuem conta no Google, poderão utilizá-la sem realizar um novo cadastro. Ao investigarmos as possibilidades de uso dessa ferramenta percebemos que:

A construção de aplicativos não se limita a jogos simples. Você também pode criar aplicativos que informam e educam. Você pode criar um aplicativo quiz para ajudar você e seus colegas a estudar um teste, ou mesmo um aplicativo de criação de quiz que permite que os usuários de seu aplicativo criem seus próprios questionários [...]. (WOLBER, ABELSON, SPERTUS e LOONEY, 2011, p. 18).

A perspectiva de poder criar aplicativos que informam e educam nos faz acreditar que o App Inventor pode ser trazido para dentro do contexto escolar, juntamente com as Tecnologias Móveis, que já fazem parte do cotidiano dos estudantes fora da escola. A programação realizada pelo professor pode contribuir para seu desenvolvimento profissional, instigando sua criatividade, o estimulando a se capacitar, quanto pode aproximá-lo de seus alunos.

Apesar de o software não exigir formação em programação para seu uso, e possuir um ambiente intuitivo e facilitador na criação de aplicativos, acreditamos que o professor necessita de uma ambientação com a ferramenta antes de utilizá-la. É um desafio, mas conforme pontua Oliveira (2016), é tarefa do professor adaptar suas práticas escolares de forma a acompanhar o avanço das tecnologias, usando-as de maneira tal que as mesmas venham a favorecer o bom andamento de suas aulas. 
Acreditamos que buscar compreender o funcionamento do App Inventor, bem como trazer o mesmo para dentro do contexto escolar, pode contribuir com os processos de ensino e de aprendizagem de matemática.

E ainda, como cita Moura (2014), essa ferramenta apresenta "interface agradável, torna a criação de aplicativos simples, não exigindo os de experiência". Diante dessa possibilidade, não precisamos ficar presos a um único recurso tecnológico como um computador individual, pois, sua plataforma encontra-se na nuvem ${ }^{1}$, além de ser algo que possivelmente proporcionará aos estudantes um vínculo maior com o ensino, já que o mesmo está acontecendo a partir de seu recurso tecnológico pessoal.

O objetivo dessa pesquisa foi verificar como ocorre a programação de aplicativos por professores de matemática através do software App Inventor e como se dá a utilização desses aplicativos pelos alunos.

\section{MetOdOLOGIA}

Para realização dessa pesquisa, utilizamos uma metodologia qualitativa descritiva, pois nosso foco é apresentar o processo de construção dos aplicativos no software App Inventor, bem como a exploração dos mesmos em sala de aula. Para Godoy (1995, p. 63), "os pesquisadores qualitativos estão preocupados com o processo e não simplesmente com os resultados do produto". Para realizar discussões quanto aos conteúdos que escolheríamos para aplicação do projeto, bem como para realizar a programação dos aplicativos, foram necessárias algumas reuniões entre os pesquisadores. Escolhemos os conteúdos iniciais do 2o bimestre do ano letivo de 2017: Sequências Numéricas e Progressões Aritméticas. Quando iniciamos a programação dos aplicativos, planejamos que a utilização dos mesmos ocorreria no

\footnotetext{
${ }^{1}$ Está relacionado à internet, ou seja, à utilização da memória e da capacidade de armazenar em servidores e computadores interligados e compartilhados via rede de internet.
} 
início do 2 o bimestre letivo. Assim, selecionamos os conteúdos que estariam sendo trabalhados durante este período, conforme o planejamento anual da professora de matemática, uma das autoras deste artigo. Fizeram parte deste estudo 105 alunos, distribuídos em três turmas de 1a série do Ensino Médio, de um colégio da rede privada de ensino de Curitiba.

A programação dos aplicativos foi realizada pelos pesquisadores, sem auxílio de profissionais de programação, com utilização de algumas pesquisas em sites de buscas. Optamos por desenvolver um aplicativo sobre Sequências Numéricas e outro sobre Progressão Aritmética, para que pudéssemos utilizar abordagens diferentes. A programação foi realizada nos computadores pessoais dos pesquisadores, com acesso à internet, durante uma semana. Para acessar a plataforma do software, utilizamos nossas contas pessoais do Google, não sendo necessário realizar novos cadastros.

Salientamos que na etapa de utilização dos aplicativos pelos alunos, procuramos identificar os efeitos provocados pela utilização dessa tecnologia, inclusive no que se refere ao envolvimento e motivação dos alunos. Acreditamos que estudantes mais envolvidos e motivados em sala conseguem aprender mais. "O uso criativo das tecnologias pode transformar o isolamento, a indiferença e a alienação com que costumeiramente os alunos frequentam a sala de aula, em interesse e colaboração" (KENSKI, 2011, p. 103).

Destarte, criamos um grupo em um aplicativo de mensagens, o WhatsApp, com o nome "Celular na matemática", no qual foram disponibilizados os aplicativos para que os alunos fizessem o download e os instalassem nos seus celulares.

Os conteúdos foram trabalhados em duas semanas de aula, em dez aulas de cinquenta minutos. Nas duas primeiras aulas, o conteúdo abordado foi o de Sequências Numéricas. Para a abordagem do conteúdo de Progressão Aritmética, foram utilizadas oito aulas. 
O aplicativo "Sequências Numéricas", que passaremos a chamar de Aplicativo 1, foi utilizado ao final da primeira aula, após a explanação do conteúdo. Na aula seguinte, conversamos com os alunos sobre a utilização do aplicativo e eles resolveram alguns exercícios.

O conteúdo de Progressão Aritmética foi trabalhado durante quatro aulas, através de abordagens sem utilização de aplicativos, com aulas expositivas, resolução de exercícios e exemplos. Uma lista de exercícios foi entregue aos alunos na aula subsequente. Em seguida, durante duas aulas, disponibilizamos o aplicativo "Progressão Aritmética", que chamaremos de Aplicativo 2. Foram apresentadas situações-problema para que os alunos resolvessem utilizando o aplicativo. Na última aula da pesquisa, os alunos receberam uma lista de exercícios com o mesmo grau de dificuldade da primeira lista realizada para verificar se houve alguma modificação na forma de resolução dos exercícios após o contato com o Aplicativo 2. Após a utilização dos aplicativos, utilizamos o grupo criado no WhatsApp para questionar aos alunos suas percepções sobre as atividades realizadas.

Vale pontuar que realizamos a análise dos dados da pesquisa em duas etapas. A primeira se refere à programação dos aplicativos, na qual procuramos observar se programar no software App Inventor é algo plausível para professores. A segunda etapa é relativa à utilização dos aplicativos em sala de aula.

Para análise da primeira etapa, utilizamos, como instrumentos, as anotações e observações dos pesquisadores e a própria programação desenvolvida. Os dados produzidos que embasaram a análise da segunda etapa, foram verificados a partir de registros escritos pelos pesquisadores durante as aulas, gravações em áudio e vídeo, fotografias e os registros no grupo de WhatsApp.

\section{RESULTADOS E DISCUSSÃO}


Para uma melhor compreensão quanto aos resultados desta pesquisa, apresentamos na sequência do texto como se deu a programação dos aplicativos, bem como a forma de utilização dos mesmos em sala de aula e suas contribuições pedagógicas. Trazemos também as impressões que os alunos tiveram em relação ao uso desta tecnologia nas aulas de matemática.

\subsection{Programação dos Aplicativos}

Sabemos que "tecnologias digitais não promovem significativos avanços nos processos educacionais por si só" (FERREIRA; MATTOS, 2015, p. 275). Por isso, criamos aplicativos que permitiram aos alunos identificar e corrigir seus erros, desenvolvendo o raciocínio e criando estratégias para resolver exercícios e, com isso, avançando no processo de aprendizagem dos conteúdos estudados.

Ao iniciarmos a utilização do software App Inventor, verificamos que ele se apresentava em inglês. Contudo, observando a tela inicial do mesmo, identificamos a opção de alterar para outros idiomas, inclusive o Português do Brasil, conforme a Figura 1. Acreditamos ser um ponto positivo, pois alguns professores poderiam se inibir ao programar em inglês.

Figura 1: Tela de Design, indicando a versão Português do Brasil. Fonte: http://ai2.appinventor.mit.edu/. 


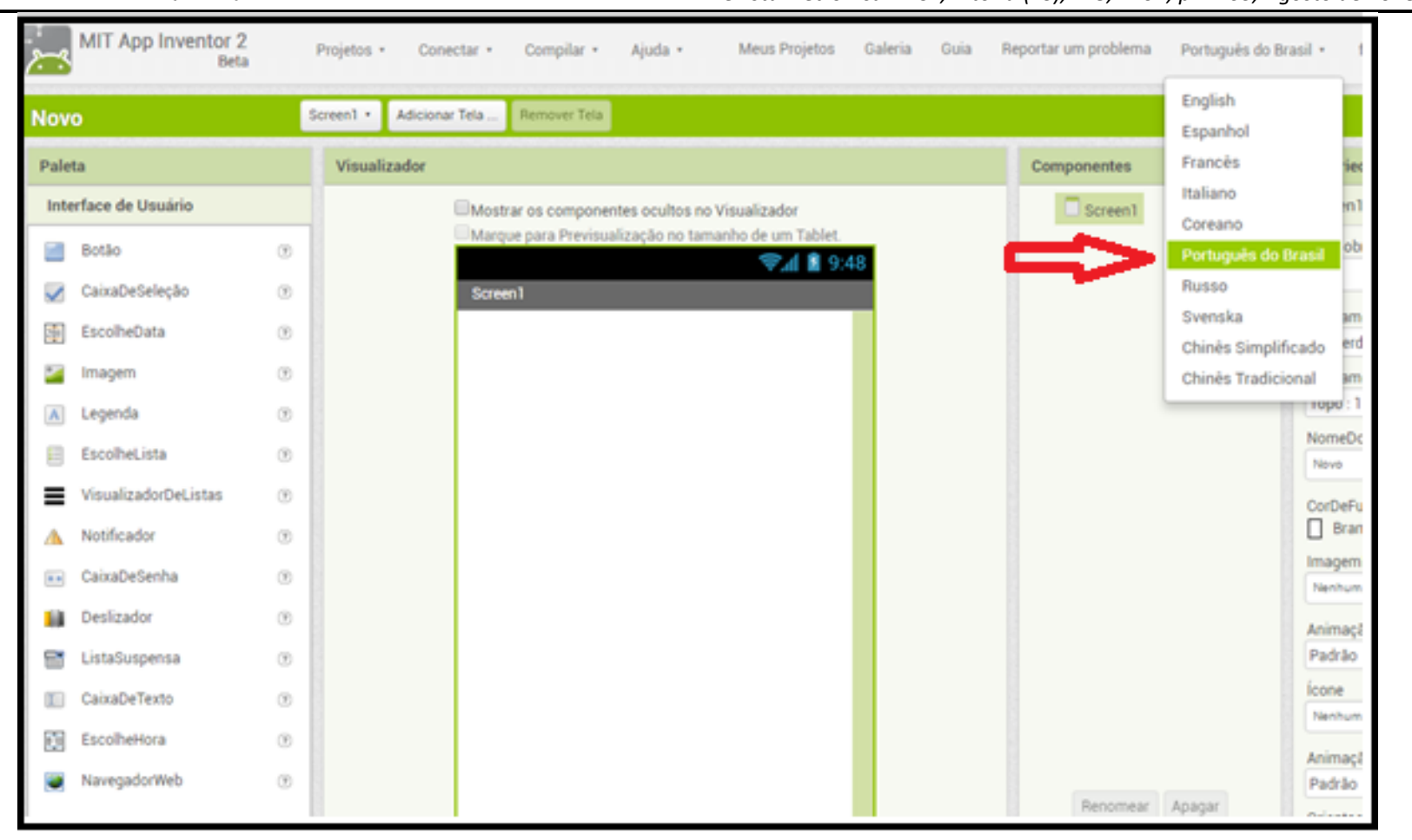

Identificamos intuitivamente que a primeira tela apresentada no software se referia à tela do celular. Assim, seria nela que deveríamos criar o layout que nossos aplicativos teriam. Observamos cada item da paleta do canto esquerdo para verificar as possibilidades de inserção que teríamos. Fizemos alguns testes, adicionamos botões, e os configuramos em cores e tamanhos diferenciados utilizando o canto direito da tela do software. Percebemos que era possível importar imagens para serem colocadas no layout e sons ou filmes que poderiam ser utilizados na programação. Fizemos importações de figuras e sons com formatos variados e os mesmos foram aceitos pelo software. Depois de alguns testes percebemos que a configuração dessa tela inicial não seria difícil, exigindo apenas formatações rotineiras em atividades no computador, como renomear, mudar a cor, formato, tamanho e posição dos objetos.

Para cada botão ou ícone acrescentado na tela de layout é possível inserir alguma função ou comando. Para isso, é necessário acessar o campo de programação, 
disponível na opção "Blocos". Nesse campo, os ícones que foram criados no layout encontram-se disponíveis. É possível arrastá-los para especificar suas ações.

Fizemos um pequeno teste adicionando um único botão no layout e programando que ele emitisse um som ao ser clicado. Para disponibilizar o aplicativo teste em nossos celulares utilizamos a opção "Compilar". Existem dois modos de disponibilização do aplicativo no celular: por código, do tipo QR-code², o que exige a instalação de um aplicativo leitor de código, ou por link, através do acesso à internet. Diferentes aplicativos leitores de códigos estão disponíveis de maneira gratuita, por isso consideramos que as duas formas de disponibilização dos aplicativos programados a partir do App Inventor são convenientes e fáceis. Após verificar que o aplicativo teste ficou funcional, iniciamos a programação de dois outros para as aulas de matemática.

O Aplicativo 1 foi criado em forma de Quiz ${ }^{3}$. (Ver Figura 2). Foram desenvolvidas algumas telas no software, com Sequências Numéricas diferentes para que o aluno calculasse o termo subsequente. A criação dessas telas exigiu um trabalho relativamente longo, pois o software não permite a cópia de itens de uma tela para outra. Foi preciso importar figuras com as Sequências, feitas no Paint ${ }^{4}$. Os botões com as respostas foram criados no próprio App Inventor. Cada Sequência obedece uma regra diferente, a qual o aluno precisa descobrir, desenvolvendo seu raciocínio. Ele só tem acesso à tela seguinte caso acerte o próximo termo de cada Sequência. Criamos mensagens de felicitações para os casos de acertos e de estímulo para os casos de erros, possibilitando que o aluno possa repensar sua resposta e alterá-la. Na última

\footnotetext{
${ }^{2}$ Código com barras bidimensionais que pode ser escaneado através das câmeras da maioria dos smartphones comercializados hoje.

${ }^{3}$ Nome dado a um jogo de perguntas e respostas.

${ }^{4}$ Software utilizado para a criação de desenhos simples e também para a edição de imagens. O programa é incluso, como um acessório, no sistema operacional Windows, da Microsoft.
} 
tela do aplicativo, programamos um campo para o aluno colocar seu nome e uma instrução de que deve enviar o print da tela para sua professora.

Figura 2: Telas do Aplicativo 1. Fonte: Os autores.

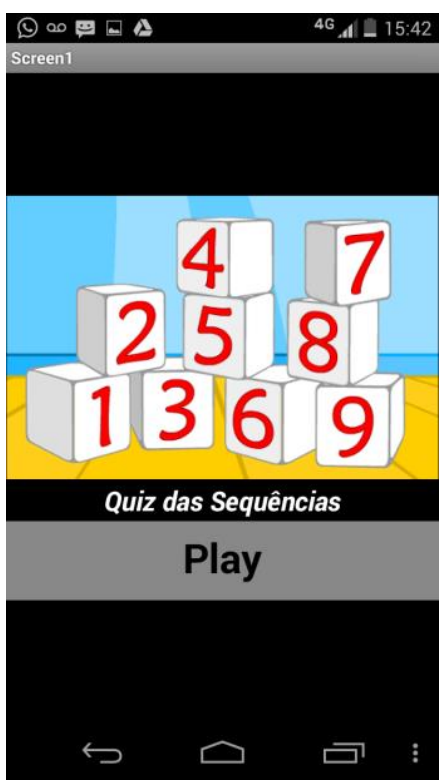

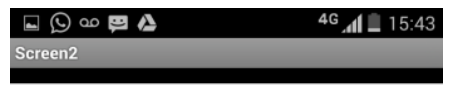

Qual o próximo termo da sequência $(2,5,8, \ldots)$ ?

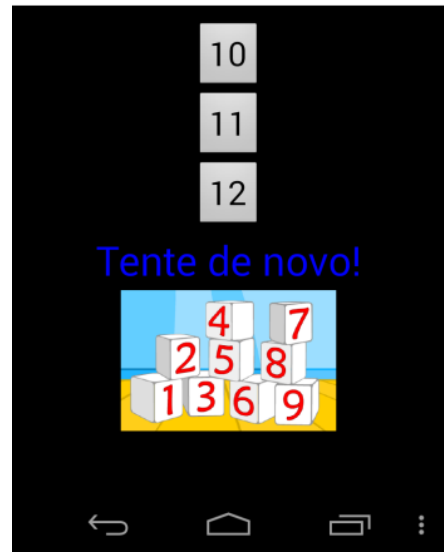

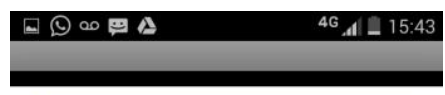

Qual o próximo termo da sequência $(2,6,18, \ldots)$ ?

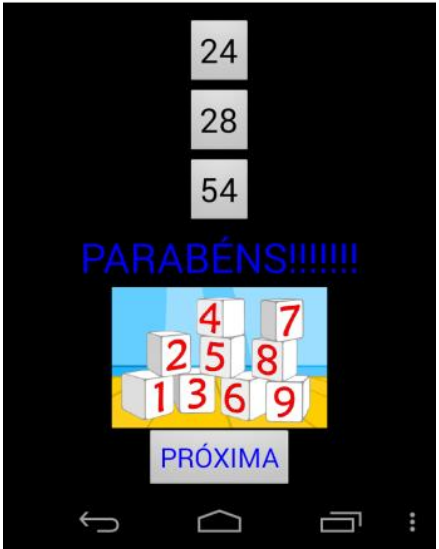

A programação do funcionamento do Quis demandou um trabalho menor em relação à criação do layout, pois na guia de programação é prevista a cópia de procedimentos. Programamos que ao clicar na alternativa certa o aluno receberia uma mensagem de felicitação e o aplicativo mostraria a próxima tela. Caso contrário, receberia outra mensagem e a tela não mudaria. Para descobrir como informar o software que deveria avançar para a próxima tela, procuramos informações em sites de busca e encontramos alguns tutoriais em português. Tomamos o cuidado de que o botão "Próxima" só aparecesse na tela após a resposta certa ter sido selecionada, para não permitir que o aluno avançasse de uma tela a outra sem resolver a Sequência proposta. Assim, o aluno teria a oportunidade de buscar novas opções de respostas para cada Sequência, sem desistir diante de um possível erro. Quando realizamos o teste com o Aplicativo 1 em nossos celulares, verificamos que tínhamos cometido um erro. Quando se clicava em uma alternativa correta após uma alternativa errada ter sido selecionada, a mensagem de erro permanecia na tela. Facilmente corrigimos o 
problema incluindo a exclusão da mensagem de erro após a escolha correta da alternativa. A programação de uma das telas pode ser observada na Figura 3.

Figura 3: Blocos de programação do Aplicativo 1. Fonte: Os autores.

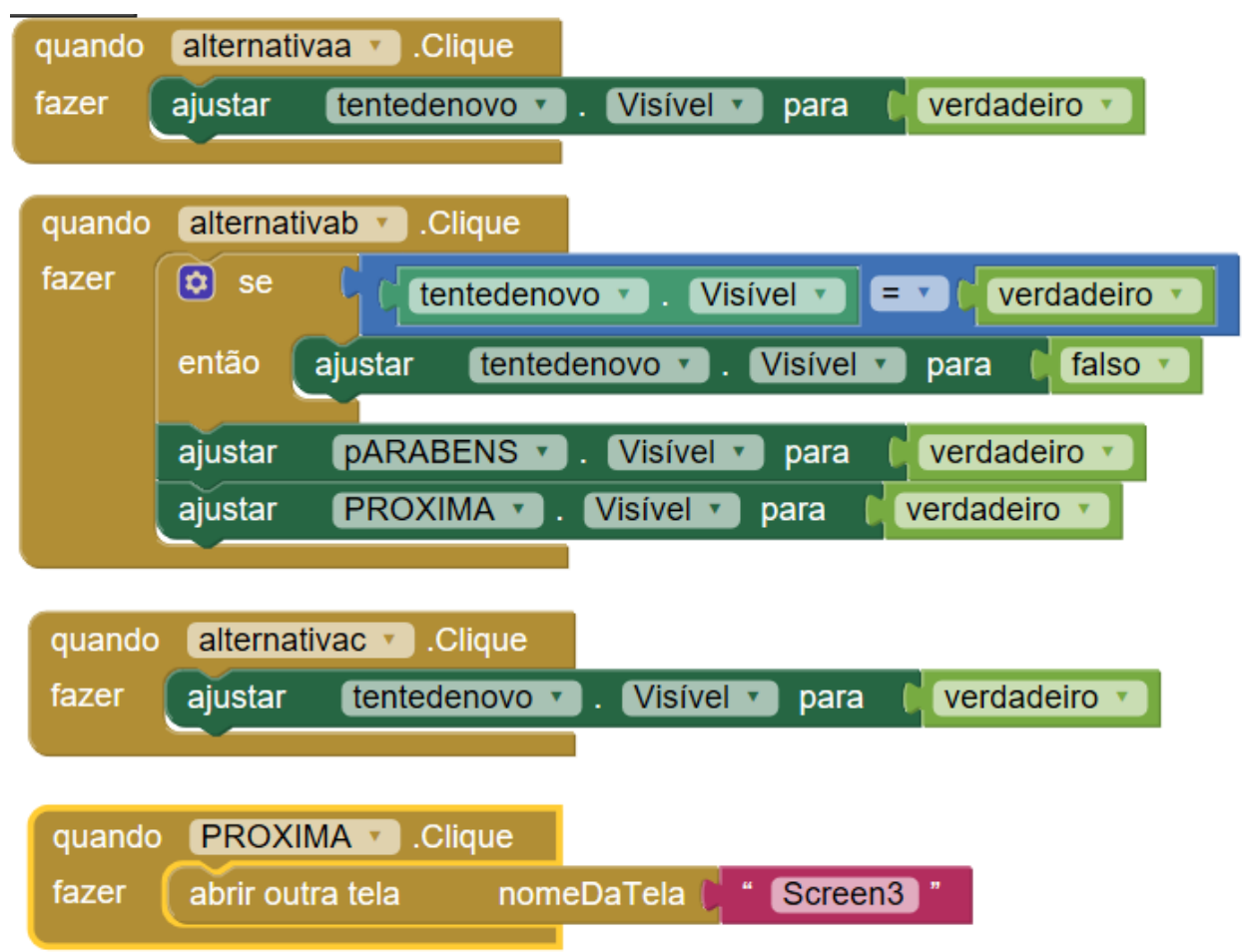

Já o aplicativo 2 é uma ferramenta para cálculo do termo geral de uma Progressão Aritmética, conforme destacado na Figura 4. Entretanto, o aplicativo fornece a opção de calcular também o primeiro termo, o número de termos ou a razão da Progressão.

Figura 4: Tela do Aplicativo 2. Fonte: Os Autores.

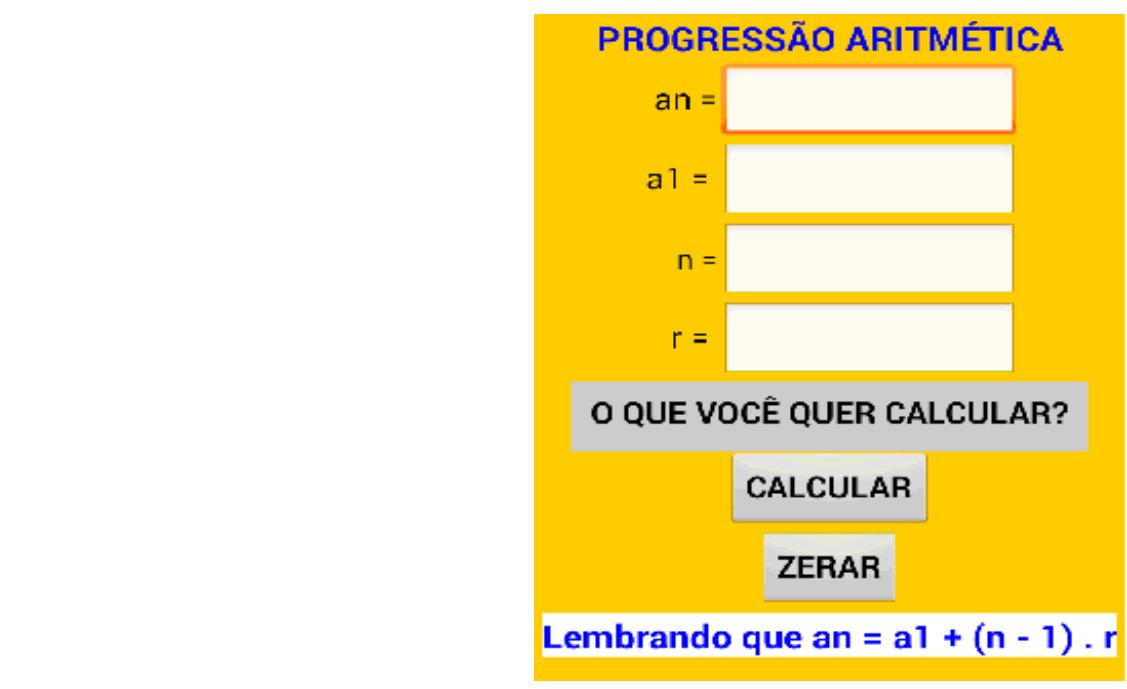


Esse aplicativo possui uma única tela, na qual o aluno deve inserir os dados conhecidos e identificar o que deseja calcular: termo geral, primeiro termo, número de termos ou razão. Como havíamos planejado que ele fosse utilizado após a explanação do conteúdo, mantivemos a linguagem matemática para designar os itens a serem calculados. O layout foi criado com caixas de textos, nas quais o aluno deveria inserir os dados conhecidos dos problemas que desejassem resolver. Três botões foram inseridos, para permitir ainda mais interação do aluno. Ao clicar em "Calcular", o aluno recebe o resultado. Criamos um layout simples e que possibilitasse uma fácil manipulação. Incluímos a opção de zerar os dados já digitados para que o aplicativo pudesse ser utilizado diversas vezes. Existe ainda o botão para o aluno escolher o que deseja calcular. Para isso criamos uma lista com as opções na, $a_{1}, n$ ou r, que aparece na tela quando clicado no botão "O que você quer calcular?”.

A programação do Aplicativo 2 exigiu atenção quanto às regras matemáticas de operações, mas também foi realizada intuitivamente através de blocos, como mostramos na Figura 5. Existe um campo na programação com o nome "Matemática", que disponibiliza as operações. Precisamos especificar o que deveria ser somado ou multiplicado, conforme a fórmula do termo geral da Progressão Aritmética. Portanto, pontuamos que os conhecimentos exigidos para a programação, foram os relacionados aos conteúdos específicos dos aplicativos e não os de programação.

Figura 5: Blocos de programação do Aplicativo 2. Fonte: Os Autores 


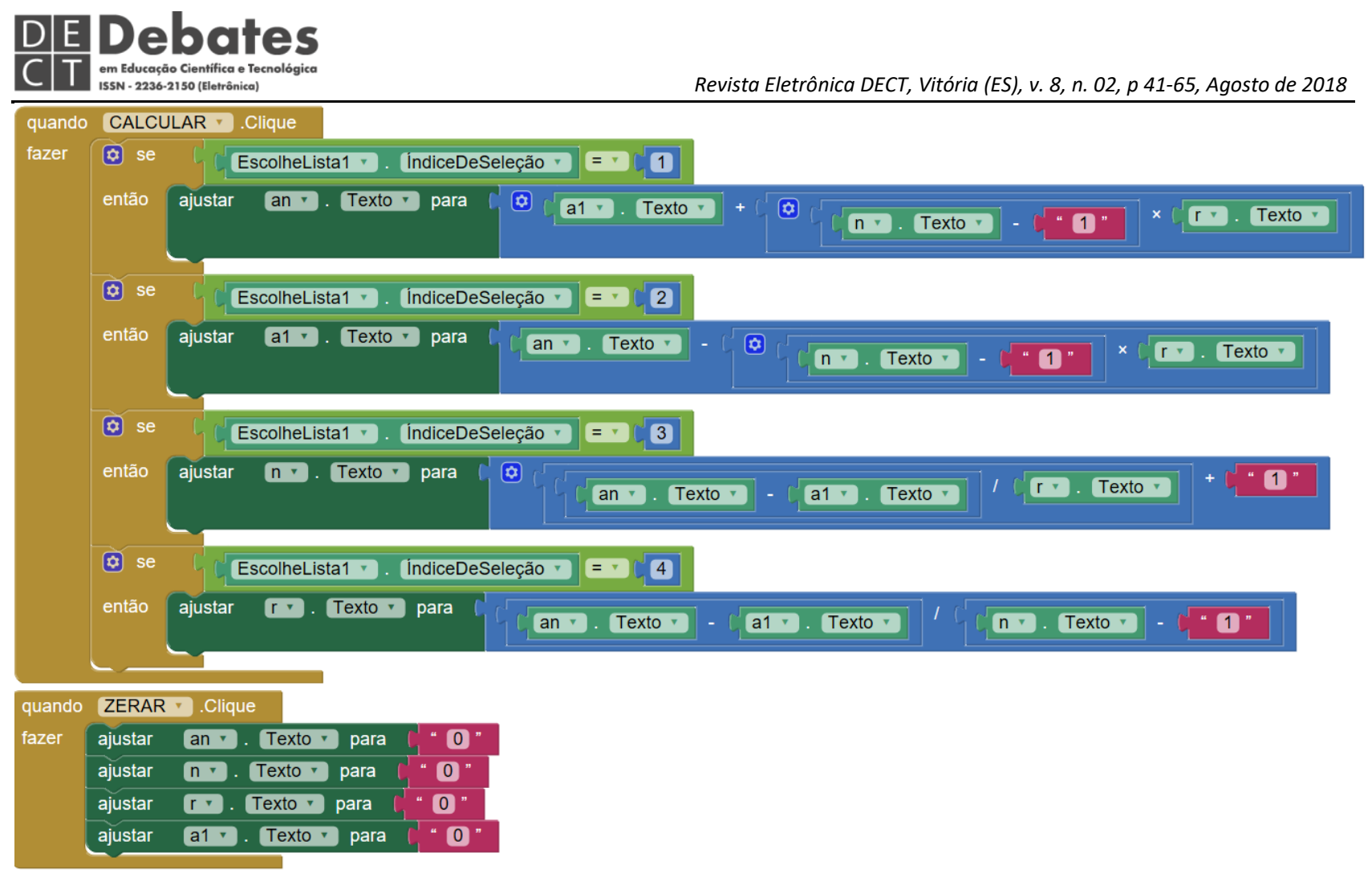

Na plataforma do programa está disponível a opção Assistente Al, conforme mostramos na figura 6. Esse assistente nos auxiliou no processo de programação, por meio do qual foi possível depurar os programas no instante em que estávamos desenvolvendo os mesmos, ou seja, o Assistente Al nos oferece uma depuração em tempo real, ao mesmo tempo em que estamos alterando algo na programação no computador, essa alteração já é vista no próprio aplicativo do celular. Utilizamos o Assistente Al para desenvolver os programas corretamente, de forma que ao levar os mesmos para a sala de aula, eles estivessem prontos para serem explorados pelos alunos.

Figura 6: Tela de Design, indicando a localização do Assistente Al. Fonte: <http://ai2.appinventor.mit.edu/> 


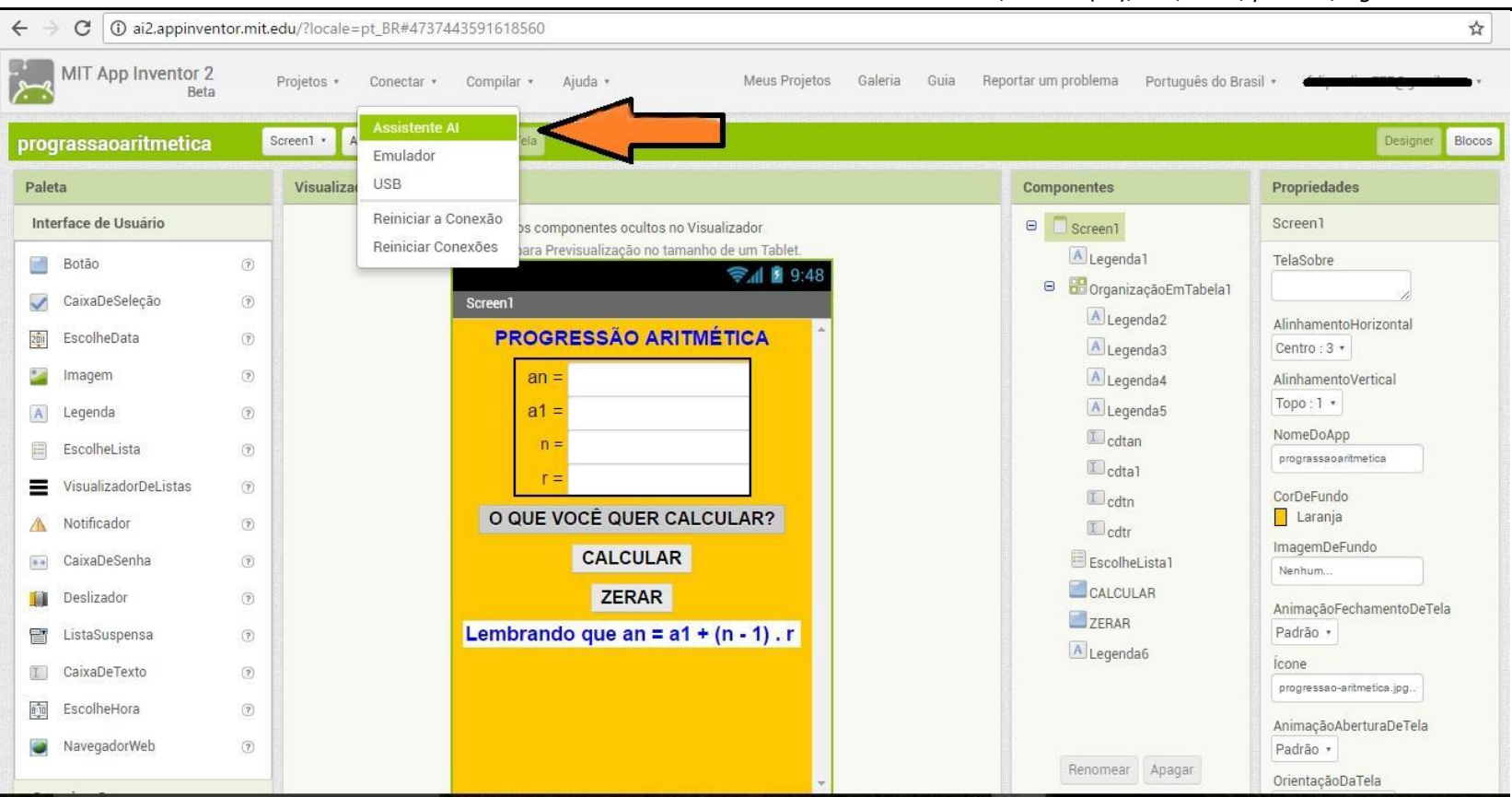

Verificamos que para a utilização criativa das tecnologias digitais é preciso que o professor seja incentivado a participar de pequenas formações continuadas em serviço, contando com a colaboração do corpo técnico escolar. Também é necessário que os profissionais da educação dominem essas tecnologias no tocante pedagógico. Para Kalinke et al (2015, p.181):

Para que o potencial das TIC aplicadas à educação seja explorado é necessário que o professor as domine, e que as novas possibilidades presentes nesses recursos se tornem ferramentas de trocas de informação e disseminação do conhecimento.

Separar um tempo para o estudo destas novas tecnologias e para o uso coerente delas dentro das salas de aula é uma inevitabilidade para professores. Kalinke (2004) pontua a necessidade desse profissional separar alguns minutos de seu tempo pessoal para se tornar apto quanto a utilização dos recursos pedagógicos que irá utilizar em suas aulas. Isso não implica necessariamente que os professores devam fazer cursos de capacitação para utilizar o App Inventor. Acreditamos que esse tempo separado para explorar as potencialidades da utilização dos celulares nas aulas de matemática seja o diferencial para os profissionais que utilizarão esses recursos juntamente com seus alunos. 


\subsection{Utilização dos Aplicativos Pelos Alunos}

Quando informamos os alunos que utilizaríamos o celular durante a aula, houve uma demonstração de satisfação por parte deles. Verificamos que alguns alunos possuíam smartphones com sistemas operacionais IOS e Windows Phone. Como já citamos, os aplicativos criados no App Inventor só são executados no sistema operacional Android, o que nos fez optar pelo trabalho em dupla para assegurar que todos os alunos teriam acesso ao aplicativo. Disponibilizamos, então, o Aplicativo 1 e os orientamos a sentarem em duplas para a utilização dele. Não houve necessidade de explicar como funcionava o aplicativo, pois eles o exploraram intuitivamente.

Foi interessante observar como os alunos se envolveram na atividade, procuraram formas de entender as Sequências Numéricas e logo concluíram o quiz, questionando inclusive se teriam mais aplicativos durante o ano. Foi possível identificar a harmonia dos alunos mencionada por Ferreira e Mattos (2015) com a atividade proposta. Na Figura 7 apresentamos a manipulação do aplicativo pelos alunos.

Figura 7: Fotos da Utilização do Aplicativo 1. Fonte: Os Autores.
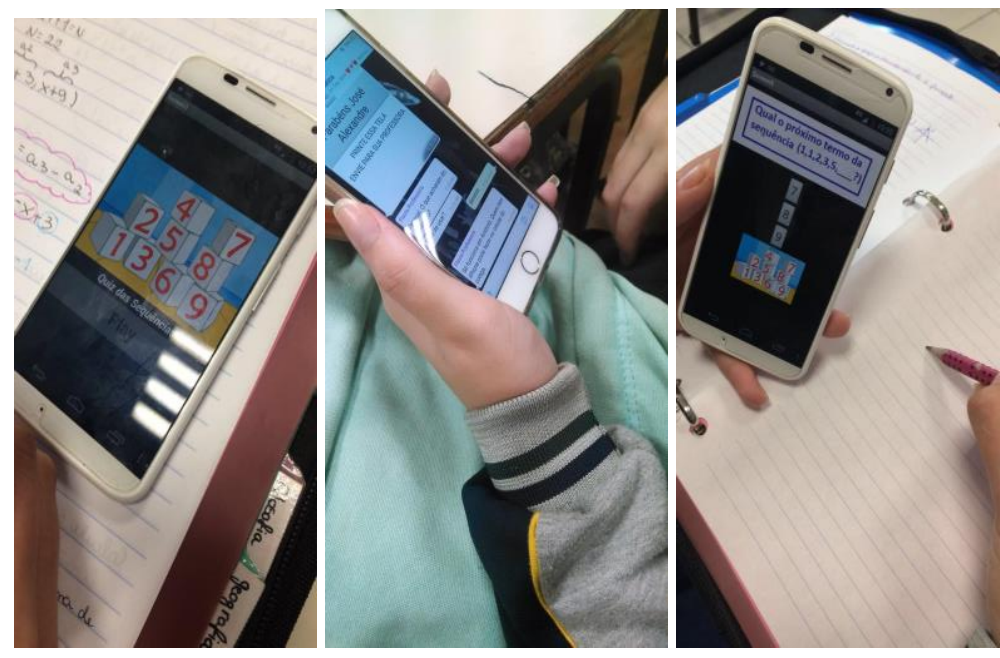

Para a utilização do Aplicativo 2, usamos uma metodologia diferente: os alunos precisavam resolver situações-problema relacionadas ao conteúdo. Dividimos a turma em grupos de 3 a 4 pessoas visando possibilitar o trabalho colaborativo. Eles 
precisavam colher os dados dos problemas, analisá-los e então digitá-los no aplicativo.

Foi uma atividade interessante, pois quando eles se equivocaram na classificação dos dados, recebiam como respostas números ora muito grandes, ora com muitas casas decimais, que sugerem erros. Os alunos precisavam discutir para descobrir o que tinham errado, corrigir no aplicativo e tentar novamente.

O que poderia ser um aplicativo mais simples, por lembrar uma calculadora, acabou gerando discussões, análise, busca de novas respostas, contribuindo para o desenvolvimento dos alunos. A utilização do Aplicativo 2 destacou a função motivadora e facilitadora do celular em sala de aula apontada por Oliveira (2016). Apresentamos na Figura 8 a manipulação do Aplicativo 2.

Figura 8: Fotos da Utilização do Aplicativo 2. Fonte: Os autores.
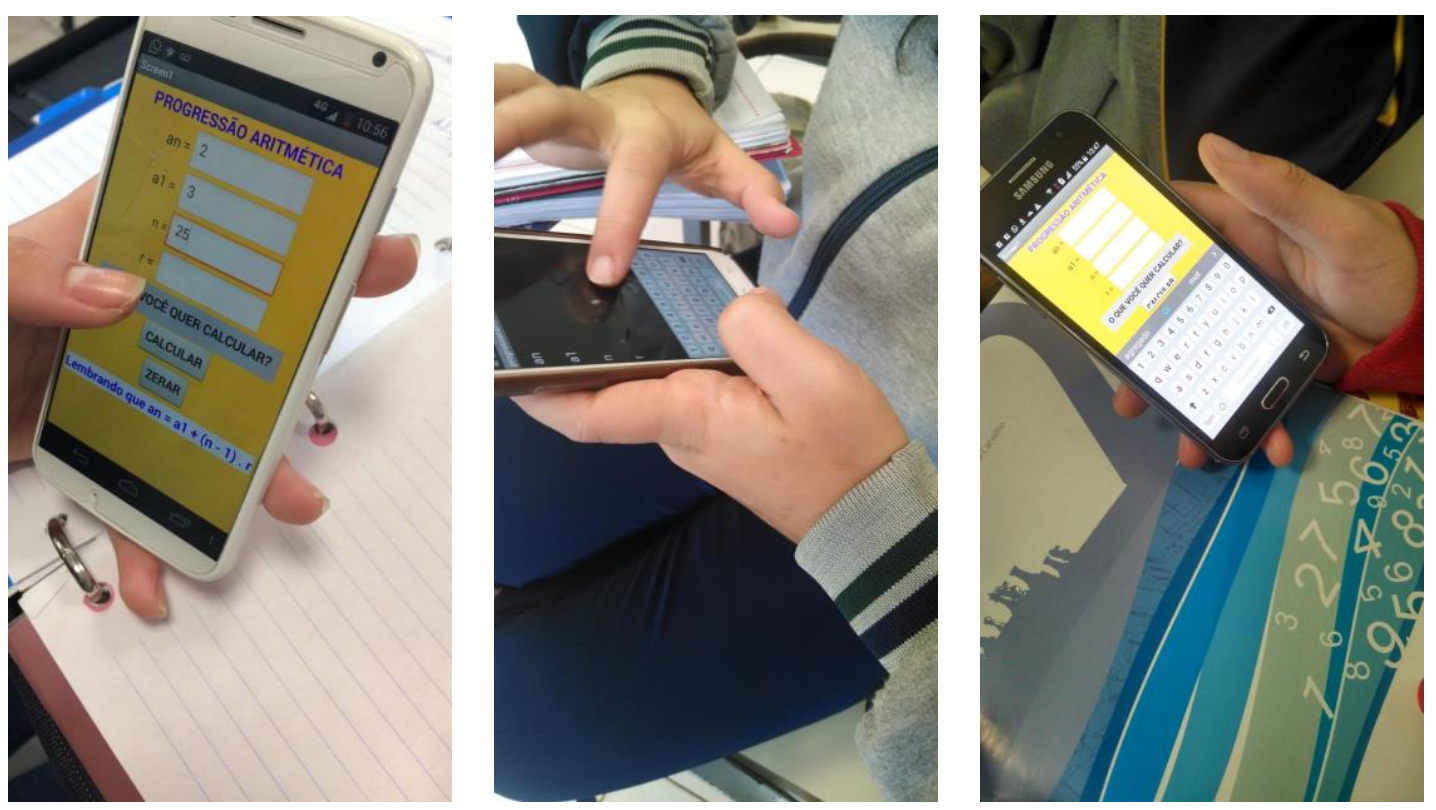

\subsection{CONTRIBUIÇÕES DO APLICATIVO}

Em relação ao conteúdo de Sequências Numéricas, observamos que os alunos compreenderam o porquê de seus erros na realização do quiz e demonstraram grande motivação para continuar aprendendo. No Aplicativo 1, os alunos observavam a sequência apresentada na tela e precisavam identificar o próximo termo. Notamos que os alunos estavam com lápis e caderno à disposição, mas fizeram os cálculos

\section{(cc) Br-No-ND}


mentalmente. A atividade demonstrou-se prazerosa: os alunos riam e comemoravam quando acertavam a resposta, mesmo que em uma segunda tentativa. Com isso, acreditamos que realizar um trabalho utilizando os celulares, que os alunos já trazem consigo, pode proporcionar verdadeiro envolvimento e comprometimento dos estudantes com o ensino que é ofertado dentro das salas de aula, pois, conforme cita Lévy (1993, p. 24):

É bem conhecido o papel fundamental do envolvimento pessoal do aluno no processo de aprendizagem. Quanto mais ativamente uma pessoa participar da aquisição de um conhecimento, mais ela irá integrar e reter aquilo que aprender.

Para analisar se a utilização do Aplicativo 2 contribuiu de alguma forma com a aprendizagem, comparamos as duas listas de exercícios realizadas pelos alunos. Na primeira, observamos um erro comum: na coleta de dados eles trocavam o termo geral pelo número de termos da Progressão Aritmética. Isso aconteceu com uma frequência menor na segunda lista, nas três turmas que usaram o aplicativo. Quando cometiam esse erro, o resultado absurdo chamava a atenção e os levava à reflexão. Como era fácil corrigir o erro, readequando os elementos e pedindo um novo cálculo, os alunos se mantinham motivados a refazer os procedimentos até chegarem no resultado que julgavam correto. Assim como Davis e Espósito (2007), acreditamos que “ [...] o erro deve ser encarado como resultado de uma postura de experimentação, onde a criança levanta hipótese, e, planeja uma estratégia de ação e a põe à prova". As reflexões fizeram com que eles começassem a diferenciar melhor o termo geral do número de termos, acertando mais exercícios na segunda lista, o que sugere um avanço acadêmico, pois essa troca do termo geral pelo número de termos é algo comum entre estudantes.

\subsection{FeEdBACK dOS Alunos}


Os alunos foram entrevistados no grupo do WhatsApp sobre como se sentiram utilizando o celular para a aprendizagem. Através de respostas escritas e Emojis ${ }^{5}$ conforme mostramos na figura 9, demonstraram que gostaram da experiência e gostariam de repeti-la em outras disciplinas. Concluíram ser simples a utilização do celular para aprender e ressaltaram como o relacionamento deles se fortaleceu. Destacaram que a matemática fica mais atrativa com a utilização de aplicativos e do celular em sala. Acreditamos que as tecnologias dentro do espaço escolar estão a serviço das práticas de sala de aula, em especial das aulas de matemática, pois, conforme citam Motta e Silveira (2010, p.116):

A informática está a serviço do ensino e aprendizagem da matemática, pois proporciona ao aluno a criação de uma imagem diferente da disciplina, bem como o enriquecimento de práticas pedagógicas que desenvolvem a exploração, a criatividade, a ludicidade, o raciocínio lógico, a interatividade, a socialização, a afetividade e a reflexão.

Percebemos que é possível proporcionar aos alunos uma relação mais estreita com a disciplina de matemática através da utilização das Tecnologias Móveis. E pontuamos que o software App Inventor nos proporcionou o uso destas tecnologias de forma mais pessoal com os conteúdos matemáticos, selecionados pelos professores.

Figura 9: Exemplos de Interação dos Alunos no Grupo de WhatsApp. Fonte: Os Autores.

${ }^{5}$ Imagens utilizadas em aplicativos para representar palavras ou emoções. 


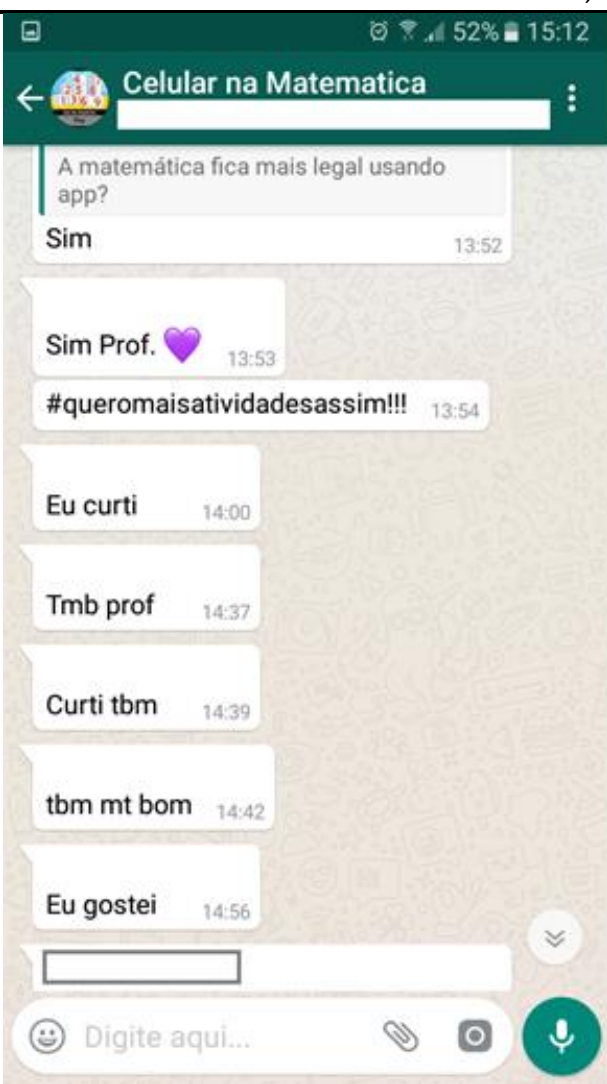

\section{CONSIDERAÇÕES FINAIS}

Para acompanhar as mudanças da sociedade, especialmente no desenvolvimento da tecnologia nos últimos anos, a escola precisa mudar. Com isso é necessário se abrir ao novo. Sabemos que o uso de tecnologias não é o único caminho de mudança. Porém, tivemos a oportunidade de vivenciar essa experiência e enxergar uma possibilidade de bons resultados através do uso do celular em sala, com a utilização de aplicativos desenvolvidos através do software App Inventor. Essa experiência foi motivadora para os pesquisadores, pois programar aplicativos personalizados, de forma intuitiva, sem necessidade de conhecimentos de linguagem de programação, pensando nos alunos que irão utilizá-los e escolhendo conteúdos específicos para serem trabalhados em sala, torna mais pessoal a utilização de tecnologias. Para os alunos, manusear o aplicativo no próprio aparelho celular e saber que ele foi programado por uma equipe na qual a professora faz parte causou uma 
grande empolgação. Os alunos ficaram impressionados ao saber que o aplicativo não era comercializado, mas havia sido planejado exclusivamente para eles.

Um de nossos objetivos era de verificar como acontecia a programação de aplicativos por professores de matemática através do software App Inventor, e com isto, percebemos que esta situação exigiu dos professores/pesquisadores um tempo de dedicação para a familiarização inicial com o mesmo. Embora concordemos que a programação a partir deste software acontece de forma intuitiva, percebemos que é necessário um preparo por parte dos professores para conhecer suas possibilidades e potencialidades. Após essa familiarização percebemos que houve facilidade para desenvolver os aplicativos. Verificamos que é possível ainda, programar aplicativos para diferentes conteúdos. Acreditamos então que a exploração contínua da plataforma do App Inventor propicia cada vez mais prática e facilidade para desenvolver aplicativos que os alunos apreciem utilizar durante as aulas. Com isso, conforme já citamos, cabe ao professor investir tempo para conhecer essa tecnologia e utilizá-la dentro de sala de aula.

Outro objetivo que colocamos inicialmente em nossa pesquisa era de verificar como se dá a utilização desses aplicativos pelos alunos e apresentamos isto através das impressões que eles apontaram, citadas anteriormente no texto. Apesar da boa receptividade por parte dos alunos, percebemos uma apreensão por parte da equipe pedagógica e colegas professores durante as semanas de pesquisa. Havia uma inquietude se a possibilidade de usar o celular atrapalharia a aprendizagem, dispersaria os alunos, incomodaria os pais, estimularia os alunos a usarem o celular indevidamente, em outras aulas. Após observarem a motivação dos alunos, alguns dos profissionais que estavam apreensivos demonstraram interesse em aprender a programar aplicativos para suas aulas. Fica então a necessidade de se pensar em como mudar ou pelo menos amenizar esse preconceito, essa resistência. Outras pesquisas 
sobre o papel da escola frente a esse novo aluno digital precisam ser realizadas para que a escola deixe de ser analógica e possa também se digitalizar. E ainda, outras pesquisas sobre as possibilidades de uso do software App Inventor precisam ser realizadas, especialmente dentro do contexto escolar, para que o mesmo seja levado aos alunos em aulas de diferentes disciplinas, enriquecendo, assim, o aprendizado das mesmas.

\section{REFERÊNCIAS}

ANGOTTI, José Peres. Ensino de Física com TDIC. 1ạ ed. rev. Florianópolis, 2015.

BARBOSA, Marcos Alberto. Desenvolvendo Aplicativos Para Dispositivos Móveis Através do MIT App Inventor 2 nas Aulas de Matemática. 2016. 142 f. Dissertação (Mestrado Profissional em Matemática em Rede Nacional). Universidade Estadual de Santa Cruz. 2016.

BRANDÃO, Daniel; VARGAS, Ana Carolina. Avaliação do uso de tecnologias digitais na educação. In: Experiências avaliativas de tecnologias digitais na Educação. São Paulo: Fundação Telefônica Vivo, 2016.

CAPPELIN, Alcione; NAVARRO, Eloisa Rosotti; KALINKE, Marco Aurélio; RIBEIRO, Mariana. Capacitando Educadores Municipais Para o Uso da Lousa Digital: um caso bem-sucedido. ÀGORA, Porto Alegre, Ano 6, jul/dez. 2015. ISSN 2175-3792

COX, Kenia Kodel. Informática na Educação Escolar. Campinas: Autores Associados, 2003.

DAVIS, Cláudia; ESPÓSITO, Yara Lúcia. O papel e a função do erro na avaliação escolar. Revista Brasileira de Estudos Pedagógicos, v.72, n.171, 2007.

FERREIRA, Helenice Mirabelli Cassino; MATTOS, Rafael Arosa de. Jovens e celulares: implicações para a Educação na era da conexão móvel. In: PORTO, Cristiane; SANTOS, 
Edméa; OSWALD, Maria Luíza; COUTO, Edvaldo (Orgs). Pesquisa e Mobilidade na Cibercultura. Salvador: Edufba, 2015.

GADANIDIS, George; BORBA, Marcelo de Carvalho; SCUCUGLIA, Rodrigues da Silva. Fases das tecnologias digitais em Educação Matemática: Sala de aula e internet em movimento. Belo Horizonte: Autêntica, 2015.

GODOY, Arlida Schmidt. Introdução à pesquisa qualitativa e suas possibilidades. Revista de administração de empresas, v. 35, n.2, p. 57-63, 1995.

KALINKE, Marco Aurélio. Para não ser Um Professor do século passado. Curitiba: Chain, 2004.

KALINKE, Marco Aurélio; DEROSSI, Bruna; JANEGITZ, Laíza Erler; RIBEIRO, Mariana Silva Nogueira. Tecnologias e Educação Matemática: um enfoque em lousas digitais e objetos de aprendizagem. In: KALINKE, Marco Aurélio; MOCROSKY, Luciane Ferreira (Orgs). Educação Matemática: pesquisas e possibilidades. Curitiba: Ed. UTFPR, 2015.

KENSKI, Vani Moreira. Educação e Tecnologias - O novo ritmo da informação. Campinas, SP: Papirus, 2011.

LÉVY, Pierre; DA COSTA, Carlos Irineu. Tecnologias da Inteligência, As. Editora 34, 1993.

MOTTA, Marcelo Souza; SILVEIRA, Ismar Frango. Contribuições do Superlogo ao ensino de geometria. In: Revista Informática na Educação: teoria e prática, v.13, n.1, p. 115-127, 2010.

MOURA, Fabiana Alves Dinis de. O Design Instrucional de um Aplicativo M-Learning à Educação Matemática: Focando o Desenvolvimento de Atividades-Referentes-AFunções-Trigonométricas-Com-Tecnologias-Móveis. 2014. 171 f. Dissertação (Mestrado em Ensino de Ciências e Matemática). Universidade Luterana do Brasil. Canoas. 2014. 
OLIVEIRA, José Marcelo Velloso de; Criação de Aplicativo para Dispositivos Móveis e

sua Utilização como Recurso Didático em Aulas de Geometria Analítica. 2016. 181 f.

Dissertação (Mestrado Profissional em Matemática em Rede Nacional). Universidade Federal Rural do Rio de Janeiro. 2016.

VALENTE, José Armando et. al. O Computador na Sociedade do Conhecimento. Campinas: Unicamp, 1999.

WOLBER, David; ABELSON, Hal; SPERTUS, Ellen; LOONEY, Liz. App Inventor Create Your Own Android Apps. O’Reilly Media, Inc. Cambridge, 2011. 